\title{
Application of Spatial Mobility Research as a Tool for Site Planning on a Micro-Regional Level
}

\author{
E. Drápela* \\ Division of Road Safety and Traffic Engineering, CDV - Transport Research Centre, Brno, Czech Republic \\ * Corresponding author: emil.drapela@cdv.cz
}

\begin{abstract}
Spatial mobility research on a micro-regional and sub-regional level represents a strong tool for transport planning allowing flexible and effective reaction to the transport needs of citizens. This article deals with the methodologies of the implementation of spatial mobility research on a municipal level (municipalities and city districts) and the options of using the results for regional development needs. Untraditionally the main emphasis is not on the central metropolitan regions but rather on the contrary, on the rural areas where the principal factor to be focused on is not smooth traffic, but the accessibility of all places. This factor is connected with the risk of social exclusion of the less mobile country inhabitants resulting in a decrease in their quality of life. A well performed spatial mobility research on the micro-regional to sub-regional level may function as a traffic SWOT analysis, though, pointing out risks connected with the mobility of the population and revealing opportunities for regional development stimulation.
\end{abstract}

KEY WORDS: Transport geography, transport sociology, quality of life, spatial mobility research, public transport.

\section{INTRODUCTION}

Economic growth, accompanied by the increasing living standards of the population, is inseparably connected with an increased demand on the transport network capacity, caused, among other things, by the growing mobility of the population. The options for increased effectiveness of transport network planning include monitoring (as far as permitted by the law) the mobility of the population for current transport performance mapping. Transport performance may be analysed either indirectly, by means of a transport census, or directly by means of spatial mobility research. The inputs from transport census provide valuable quantitative data thanks to which it is possible to apply geographic modelling to the creation of relatively realistic development models. This information is sufficient from a technical point of view. On the other hand, what also needs mapping are the reasons for certain transport-related behaviour of the population and the related social changes which may also reflect to a significant extent in future development. These qualitative data on transport-related behaviour of the population, which may in addition be used as a data basis for corrective measures, may only be obtained through the observation of spatial mobility of the citizens.

Spatial mobility can be defined from the viewpoint of transport geography and sociology of transport as a process of movement of persons in time and space with the attributes of a poly-dimensional nature, including data on movement in time and space, on motivation for the movement (attractor data), on motivation for route selection (data on the transport 
network), qualitative data (type of transport), and various complementary data (subjective assessment of the process by the respondent, etc.). On the basis of the motivation spatial mobility can be divided into two types, forced, i.e. mobility for the reason of the necessity of sustenance, or other liabilities, and voluntary, i.e. mobility as the choice of the respondent, purely based on factors not related to basic sustenance. While at least gross data on forced mobility, represented mainly by commuting to work, may be obtained from national censuses - in the Czech Republic from the Census of Population, Houses and Apartments (the latest performed by the Czech Statistical Office in 2001), voluntary mobility informing about the lifestyle of the population and the related living standards cannot be mapped by mere censuses, and therefore more advanced research methods need to be found.

\section{SPATIAL MOBILITY RESEARCH}

Responses to the calls for more extensive data on the transport-related behaviour of the population include spatial mobility research, known under the more general term as travel surveys. This research is implemented in various forms in some advanced countries of the world (UK, Germany, the Netherlands, the U.S.A., New Zealand, and others). With regard to the scope of the investigation travel surveys can be divided into national surveys, aimed at formulations of more general trends in the transport-related behaviour of the population, and local surveys, monitoring in greater detail city-sized areas and their backgrounds, or micro-regions.

General methods of travel survey implementation include questionnaires for the respondents (individuals, or households). The usual questions cover the socioeconomic status of the respondent (age, gender, education, job, etc., or, in the case of households, data on the members living in the household, their number, structure, income, number of cars per household, etc...), his/her car (type, age, brand, average number of passengers per journey, type of drive, fuel consumption, etc...), usual destinations (locality and distance, time demand of the journey, time of the day of the journey, purpose of the journey, usual transport mode, financial demand of the journey, etc...) and routes (motivation for route selection). This questionnaire method is usually combined with a few days (mostly a week or a fortnight) of monitoring of the actual mobility through travel diaries, in which the respondents write details of all journeys during the monitored period - with data on the locality where the journey started, the destination, the route selected, the time of the journey's start and end, the transport mode used, the purpose of the journey, potential other passengers (who travelled with the respondent), etc. The travel diaries are used for overall precision of the spatial mobility data of the population, but are not always required due to the demand placed on the respondents (and the related potentially higher costs of the survey). From a psychological point of view it is sometimes interesting to compare the responses in the questionnaires to the reality recorded in the travel diaries. Sometimes the data, especially on the time demands of the journeys, are biased for different transport modes due to the respondents' personal preferences.

Even though the data of travel surveys may be very similar in nature, the options of their application vary, depending on the scope covered by the survey (the size of the area covered) and the respondents sample size. As nowhere in the world does the travel survey take the form of census, the options of utilisation of the national survey data are limited by the very fact of the limited number of respondents. Spatial mobility as a theme with a strong geographic dimension certainly deserves research into its spatial differentiation. Unfortunately, in reality only social differentiation may be studied, due to the small numbers of respondents. 


\section{NATIONAL TRAVEL SURVEYS}

Top-quality spatial mobility research on a national level is represented by the British National Travel Survey (Department for Transport, 2009), where the first stage of the research involves face-to-face contacts with the households, while the second stage is covered by seven-day travel diaries with all members of the households. In 2007 the survey addressed 15,048 households. The even distribution of the addresses allowed for the territory of UK to be divided into 684 territorial units for this purpose (PSU - primary sampling units) where the addresses were evenly generated (National Centre for Social Research, 2008). The survey is performed on a yearly basis.

A relatively long tradition since 1985 has been enjoyed by the annual Dutch National Travel Survey (SWOV, 2009). Unlike the British survey the time of monitoring the respondents is shorter -1 day - and includes a travel diary followed by an inquiry. This survey also covers the transport-related behaviour of households. The respondents are interviewed in groups by phone and e-mail, with the main emphasis laid on motivation of the respondents to cooperate (this method was adopted in 1999 in reaction to the continuously decreasing response to the inquiry). The Dutch have in fact taken over the German model New KONTIV® Design (Socialdata, 2006), which has also been used in Germany, but not on a national level and only in selected areas such as urban agglomerations (Socialdata, 2009).

Examples of surveys with a longer than annual periodicity include the American National Household Travel Survey (RITA, 2009). This survey has so far been held in 1969, 1977, 1983, 1990, 1995 and 2001-2002, with the periodicity of roughly 7 years. The most successful survey was performed in 1995 when about 68 thousand of the total number of 80 thousand addressed households responded to the inquiry. The main problem of the American surveys is their lack of homogeneity, though. While some have been based on personal visits to the respondents, others have involved phone communication. The travel diary was first used in 1995. In addition, in the past there were two different types of spatial mobility research, including the Nationwide Personal Travel Survey (NPTS) and the American Travel Survey (ATS) (see the Bureau of Transportation Statistics, 2004). Not only due to the research methodology, but also due to the absence of internationally recognised standards, incomparability of the data is an issue affecting not only the Americans, but also the Europeans, and international comparisons are therefore quite exceptional.

High-standard spatial mobility research from outside of Europe includes, for example, the annual New Zealand Ongoing Household Travel Survey (New Zealand Ministry of Transport, 2009), addressing about 2,800 households a year. The form of the survey is again the face-to-face interview, and a two-day travel diary. The most exotic localities where the spatial mobility research has ever been performed include the Republic of South Africa, where in 2003 the National Household Travel Survey (South African Department of Transport, 2007) covered a sample of 45 thousand households.

\section{LOCAL SPATIAL MOBILITY RESEARCH}

While the aim of the national travel surveys is to obtain general information about the transport-related behaviour of the population and quantify it, the regional or municipal travel surveys aim for the provision of concrete data on the situation in the region in question, subsequently used as the basis for transport and site planning. Unlike in the case of national travel surveys, the local research may be more specific, for example, asking about the exact routes of the journeys, or about the selection of the mode of transport for the different sections of the same journey in the case of multimodal transport 
use (such as the combination of walking, train and bus). Local and regional spatial mobility research, with its level of detail and diligence, may even perform the role of a case study. Of course the final structure of the implemented regional travel surveys always depends on the requirements of the client and so this is not always the case, unfortunately.

Research into the transport-related behaviour of citizens of large cities and urban regions prevails absolutely among the implemented regional travel surveys. This is more than logical - knowledge of transport-related behaviour of the citizens is most valuable where there are transport issues to be resolved, i.e. in the overpopulated metropolitan regions (see Schmeidler, 2008). Spatial mobility surveys in these areas supply data on locality and significance of the attractors, which, in combination with a socio-demographic projection of population number development in the individual parts of the city or region, represents a relatively good basis for road capacity and route planning within the area. A good example of these surveys may be the abovementioned German cities (Socialdata, 2009), the Australian metropolitan areas - Sydney (New South Wales Ministry of Transport, 2009) and Brisbane (Queensland Travel, 2008), the London Travel Demand Survey (Transport for London, 2008), or the Household Travel Survey in Washington (MWCOG, 2009).

In the rural areas and in the peripheral regions traffic collapses due to excessive travel are quite rare and therefore there are virtually no spatial mobility surveys performed in rural regions, for the main clients demanding travel surveys are transport planning offices. However, travel surveys provide information so complex that they may be used not only by urban planners and transport engineers but also by psychologists, sociologists and geographers (see Drápela, 2008). It is because the transport-related behaviour trends are affected by a number of different factors, and therefore multidisciplinary research is justified here. Spatial mobility research in peripheral rural regions is most needed, though, as the transport-related behaviour of the local population is much different from the behaviour of city populations, and the nationwide research provides for no details. The main purpose of the research would need to be changed for the rural regions, though, for while this type of survey in the urban regions usually serves the need for the development of a concept of spatial and functional layout of transport infrastructure, in the rural regions the main focus should be the creation of a concept of utilisation of the transport infrastructure as the backbone structure of regional development.

\section{SPATIAL MOBILITY RESEARCH ON A MICRO-REGIONAL AND SUB- REGIONAL LEVEL}

Before studying the spatial mobility research on the micro-regional level it needs to be said that the term micro-region means a functional nodal region defined by the range within which people commute to work, by its centre with at least $10-15$ thousand inhabitants and the background of at least another 10 thousand, i.e. a functional region defined by geographical methods and not a voluntary union of municipalities created for a purpose. The term sub-region then may be defined as any functional region whose centre is smaller than a micro-regional level centre. For a municipality to be considered at least a sub-regional centre there must be some traceable commuting to work or to school or to services in the centre from the surrounding villages.

The specific motivation for spatial mobility research in regions outside the metropolitan areas must be reflected in the very methodology of the research. This is why the purpose of the research must be clearly defined: In the first place the research should focus on the spatial localisation of the local attractors activating the need for travel in the local population, completed with qualitative information about the types of attractors, and further research into the issue of the level of utilisation of public transport means and a comparison 
of the offer to the demand. And last, but not least, the subject of the research should include a critical assessment of population mobility aimed at discovering the barriers restricting it. As for the forms and methods of the research, the inquiry may certainly want to be complemented with travel diaries confirming or denying the generalisations drawn from the questionnaires, but the need for the latter research form is not so urgent in the rural regions (in the urban environment the road density is higher and thus the travel diaries follow the exact attributes of the journeys, such as the route and the timing, which in the rural areas, regarding the thin road network and the exceptionality of traffic collapses and congestions is information which is quite easy to estimate relatively accurately), and the costs incurred may not bring information with substantial added value in comparison to the questionnaire, unlike in the cities. In addition the questionnaire may partly substitute the travel diary, if the questions are adequately posed.

\begin{tabular}{|c|c|c|c|c|c|c|c|}
\hline Why & Where & How & How long & How often & How much & Which way & Dist. \\
\hline To work & Pelhřimov & A & $20 \mathrm{~min}$. & $2 \mathrm{~T}$ & CZK 20 & 130,112 & $20 \mathrm{~km}$ \\
\hline \multicolumn{8}{|l|}{ To school } \\
\hline \multirow[t]{3}{*}{ For daily shopping } & Pelhřimov Kaufl. Lidl & A & $20 \mathrm{~min}$. & $2 \mathrm{~T}$ & CZK 40 & 130,112 & $20 \mathrm{~km}$ \\
\hline & Senožaty Flop & $\mathrm{P}$ & $5 \mathrm{~min}$. & $1 \mathrm{~T}$ & CZK 0 & $\mathrm{p}$ & $500 \mathrm{~m}$ \\
\hline & Humpolec Billa & $\mathrm{A} / \mathrm{B}$ & $12 / 20 \mathrm{~min}$. & $2 \mathrm{M}$ & CZK 26/20 & $130, \mathrm{~m}$ & $13 \mathrm{~km}$ \\
\hline \multirow[t]{4}{*}{ For special shopping } & Pelhřimov centre & A & $20 \mathrm{~min}$. & $1 \mathrm{~T}$ & CZK 40 & 130,112 & $20 \mathrm{~km}$ \\
\hline & Humpolec centre & $\mathrm{A} / \mathrm{B}$ & $12 / 20 \mathrm{~min}$. & $1 \mathrm{M}$ & CZK 26/20 & $130, \mathrm{~m}$ & $13 \mathrm{~km}$ \\
\hline & Arneštovice butcher & A & $8 \mathrm{~min}$. & $2 \mathrm{M}$ & CZK 16 & $130, \mathrm{~m}, 129$ & $8 \mathrm{~km}$ \\
\hline & Hořice ZD & A & $6 \mathrm{~min}$. & $2 \mathrm{M}$ & CZK 10 & $\mathrm{~m}$ & $5 \mathrm{~km}$ \\
\hline \multirow[t]{2}{*}{ For services } & Pelhřimov & A & $20 \mathrm{~min}$. & $2 \mathrm{M}$ & CZK 40 & 130,112 & $20 \mathrm{~km}$ \\
\hline & Humpolec & $\mathrm{A} / \mathrm{B}$ & $12 / 20 \mathrm{~min}$. & $2 \mathrm{M}$ & CZK 26/20 & $130, \mathrm{~m}$ & $13 \mathrm{~km}$ \\
\hline \multirow[t]{3}{*}{ To cultural or social events } & Pelhřimov music club & A & $20 \mathrm{~min}$. & $2 \mathrm{M}$ & CZK 10 & 130,112 & $20 \mathrm{~km}$ \\
\hline & Senožaty pub & $\mathrm{P}$ & $6 \mathrm{~min}$. & $2 \mathrm{~T}$ & CZK 0 & $\mathrm{p}$ & $600 \mathrm{~m}$ \\
\hline & Humpolec & A & $12 \mathrm{~min}$. & $1 \mathrm{M}$ & CZK 26 & $130, \mathrm{~m}$ & $13 \mathrm{~km}$ \\
\hline \multirow[t]{2}{*}{ For leisure time activities } & Senožaty tennis courts & $\mathrm{P}$ & $6 \mathrm{~min}$. & $1 \mathrm{M}$ & CZK 0 & $\mathrm{p}$ & $600 \mathrm{~m}$ \\
\hline & Senožaty football ground & $\mathrm{P}$ & $2 \mathrm{~min}$. & $2 \mathrm{M}$ & CZK 0 & $\mathrm{p}$ & $200 \mathrm{~m}$ \\
\hline \multirow[t]{2}{*}{ To visit friends } & Jihlava & A & $40 \mathrm{~min}$. & $1 \mathrm{M}$ & CZK 80 & $130, \mathrm{~m}, 523$ & $40 \mathrm{~km}$ \\
\hline & Žd'ár n. S. & A & $60 \mathrm{~min}$. & $1 \mathrm{M}$ & CZK 140 & $\begin{array}{c}130, \mathrm{~m}, 34 \\
150 \\
\end{array}$ & $70 \mathrm{~km}$ \\
\hline \multicolumn{8}{|l|}{ To offices } \\
\hline Other & Želiv swimming pool & A & $10 \mathrm{~min}$. & S & CZK 20 & 130,129 & $10 \mathrm{~km}$ \\
\hline
\end{tabular}

Figure 1: Example of mobility attractor identification with questionnaire: For a description, see the body of the article

Identification of attractors is the first stage of the socio-geographical survey of spatial mobility. Location and nature of the attractors represent the principal factors forming the transport-related behaviour of the local population, and that is why they require maximum attention. Attractors must be categorised first and then provided with attributes, such as location, distance from the place of residence, usual transport mode used to reach the attractor, the usual time spent on the way, and the frequency of this activity. Additional attributes may also include the financial demands of the journey. In practice this means that the respondent needs to be asked how, where, how long, how often and for what cost he or she commutes to work/school/shopping centre, etc. Figure 1 shows a draft questionnaire focusing on the identification of attractors, including an example of how such a questionnaire 
is to be filled out. It needs to be said, though, that in reality the questionnaires are only filled out with indicator values and figures or letters standing for the individual variants. For the purpose of this article the more descriptive variant that follows was selected.

Column 1 lists the basic attractor types while column 2 lists the individual attractors. To leave out attractors which have a small or negligible effect (such as a social event held in the municipality once a year, etc.), it is recommended to start the whole section with the question "Do you travel at least once a month to..." Where the event is important for the season it certainly must be included (see Fig. 1, row: Other). The column on the mode of transport includes letters with the following meaning: $\mathrm{A}=$ automobile, $\mathrm{B}=$ bus, $\mathrm{P}=$ walking, where more modes are used the individual letters are separate with slashes. The letters used in the "how often" column bear the following meaning: $\mathrm{T}=$ weekly, $\mathrm{M}=$ monthly, $\mathrm{S}=$ once a season, $1=$ once and $2=$ more often than once. In the route column the numbers represent road identification, $\mathrm{p}=$ foot paths and $\mathrm{m}=$ local roads. This is obviously an insufficient division; in reality the local roads would need some working numbering for the information to be complete. The last column shows the price of the transport - in reality the respondent is obviously unable to specify the price of the journey without a long calculation, especially in the case of private cars. This is why the inquirer asks about the mean fuel consumption of the respondent's car, which most respondents are able to specify more easily. About the evaluation of the part of questionnaire shown in Figure 1 - the questionnaire has been filled out by a resident of Senožaty, in the micro-region of Humpolec, who commutes to work to the more distant Pelhřimov. There he also does most of his shopping, with a preference for supermarkets along the way home. The respondent travels to work by private car with another passenger sharing the travel costs. In comparison to public transport, which is considerably slower and also more expensive in this situation, the respondent shows a clear preference for his private car. The travels to Humpolec focus on goods and services that cannot be had in Pelhrimov. In this case there is a relatively frequent connection by public transport, which is also partly used by our respondent. A positive fact is that the respondent walks to destinations within his home municipality. For journeys to less significant destinations the respondent again uses his automobile, mainly for the reason of an absolute lack of public transport to the destinations. The respondent therefore shows a strong overall dependence on his automobile. As for the routing, the respondent obviously uses the shortest routes available, most frequently along the local roads, but never along the D1 motorway, a mere $5 \mathrm{~km}$ away from his place of residence. The reason is that the motorway toll and the low demand for motorway use on the part of the respondent. Most of his attractors cannot really benefit from travel along the motorway - providing no greater travel comfort to the respondent.

This basic construction of spatial mobility research should be completed for the purpose of regional development with a subjective assessment of the respondents concerning the qualitative characteristics of the regional transport infrastructure. The most important factor should be the identification of the existing barriers to mobility, on the following three levels: in the case of travelling by passenger car or motorcycle, in the case of travelling by public transport, and in the case of walking or cycling. The question asked for the purpose of the barrier identification should be as follows (or similar): "Are there any locations or factors making your travel by car unpleasant, or even impossible, to a certain destination?" A similar question should then be asked about the public transport and about walking/cycling. The most frequently mentioned barriers to mobility in the case of car travel include poor road practicability in winter, poor condition of the road, hazardous sections of the road, poor routing, and heavy traffic (mostly mentioned by elderly people who have problems with orientation in heavy traffic). In the context of public transport most respondents complain of the small number or non-existence of connections to the individual attractor 
destinations, inconvenient location of the stops, poor connections between individual sections of the journey, and seniors criticise the physical demands of travelling by public transport, caused by the absence of benches at the stops, long waiting times, etc. Identification of barriers to walking or cycling is valuable information for the local councils, for the barriers are mostly represented by hazardous footpath sections within the municipality, not between the municipalities. Sometimes these are also critised, though, for example when the respondent walks to work to the neighbouring village, or to a bus stop to a larger village nearby, etc. The barrier information should be accompanied with data on their location, type and nature. An example of this (simplified) GIS information can be seen in Figure 2.

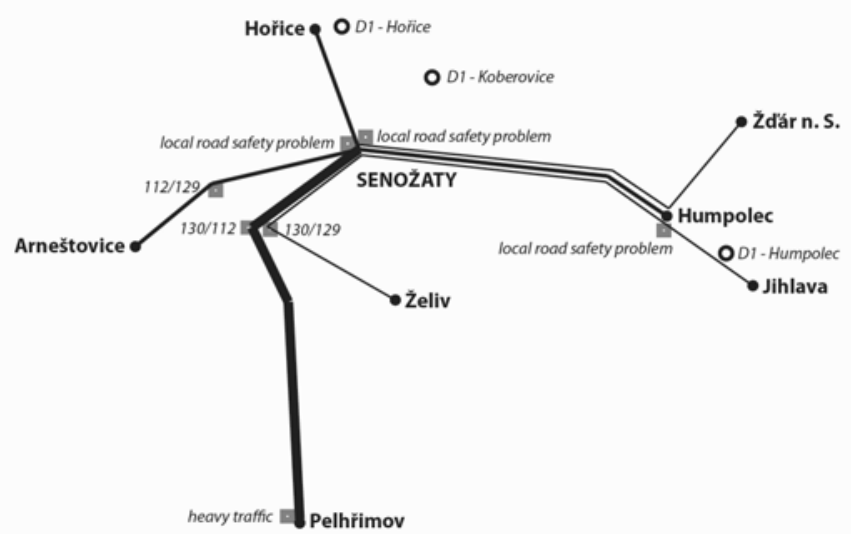

Figure 2: Example of mobility scheme for 1 inh. - line thickness presents journey frequency, black circles present limiting barriers, grey squares present inconvenient barriers

The most important issues from a regional development point of view include timing and routing of public transport lines. A conveniently organised system increases the accessibility of the individual municipalities and localities, reduces the traffic load of centres and increases the profit of the latter. Public transport is a financially demanding part of municipal budgets, which is why the relevance of every connection has to be carefully considered. The attractor data may serve as basic information for this purpose. These should, however, be completed with information about the demand for public transport, for this demand sometimes does not relate to the actual mobility behaviour of the respondents. The public transport demand should include three attributes: the time when the respondent wants to travel, the destination the respondent wants to reach and the reason why the respondent wants or needs to travel. The summary of the results of these three pillars of spatial mobility research may provide quite extensive information about both the transportrelated behaviour of the population and the mobility of the population. These data may then be used as information about the effect of transport on the quality of life of these citizens. The interpretation of the results remains the responsibility of the researcher. Attention should be paid to the identification of the reasons of population mobility preferences, to the ways of improving the accessibility of certain localities and the harmonisation of the public transport timetables, to the utilisation of the current attractiveness of certain areas for their further development or the utilisation of the development potential of the adjacent areas, and to identify and realistically assess the threats resulting from the factors manifesting themselves as mobility barriers.

\section{CONCLUSION}

Spatial mobility research, however, cannot and should not be the main research method for the development of regional development strategies, even though they may bring useful 
information at a moderate research cost. The principal advantage of spatial mobility research over the standard SWOT analysis, for example, is the relationship to the real preferences of the inhabitants and their actual problems. The results, therefore, do not represent impersonal proclamations and conclusions, but particular measures addressing particular facts. As is the case when using any soft method, a critical detachment from the respondents has to be kept, however fitting their reflections of the local situations may be. With the spatial mobility research marginalisation of certain areas with poor accessibility by transport or with little attractiveness their resulting decline may be prevented.

Spatial mobility research as a tool for site planning has been successfully tested in COST $\mathrm{C} 27^{1}$ project in Senožaty and Litenčice subregions in 2008. Altogether, questionnaires were filled in by 100 respondents. Besides the low use of the D1 motorway in the Senožaty region, the most interesting fact revealed was a commuting shift in the Litenčice region from the Bučovice area to the Kroměřiž area due to frequent closures of I/50 road.

\section{REFERENCES}

Bureau of Transportation Statistics, 2004. National Household Travel Survey (NHTS) 2001: National Data

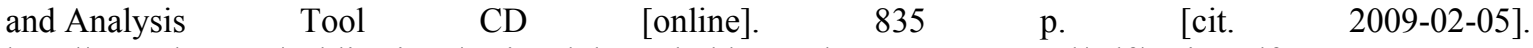
http://www.bts.gov/publications/national_household_travel_survey_2001_cd/pdf/entire.pdf

Department for Transport, 2009. Personal travel: National Travel Survey [online]. 5th February 2009 [cit. 200902-05]. $\quad<\mathrm{http}: / / w w w . d f t . g o v . u k / p g r /$ statistics/datatablespublications/personal/>

Drápela, E., 2008. Uplatnění dopravní sociologie v regionální geografii. In Miscellanea Geographica 14. Plzeň : Západočeská univerzita, Katedra geografie, 2007, pp. 27 -32. ISBN 978-80-7043-663-9

MWCOG, 2009. Household Travel Survey [online]. 5th February 2009 [cit. 2009-02-05]. $<$ http://www.mwcog.org/transportation/activities/hts/>

National Centre for Social Research, 2008. National Travel Survey 2007: Technical Report [online]. 193 p. [cit. 2009-02-05].

http://www.dft.gov.uk/pgr/statistics/datatablespublications/personal/methodology/ntstechreports/pdfntstechre p071.pdf>

New South Wales Ministry of Transport, 2009. Household Travel Survey Data [online]. 5th February 2009 [cit. 2009-02-05]. <http://www.transport.nsw.gov.au/tdc/house-survey.html>

New Zealand Ministry of Transport, 2009. Travel Survey [online]. 30th January 2009 [cit. 2009-02-05]. $<$ http://www.transport.govt.nz/ongoing-travel-survey-index/>

Queensland Travel, 2008. South East Queensland Travel Survey [online]. 21st November 2008 [cit. 2009-02-

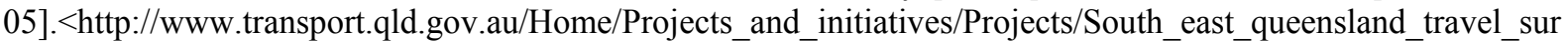
vey/>

RITA, 2009. National Household Travel [online]. 5th February 2009 [cit. 2009-02-05]. http://www.bts.gov/programs/national_household_travel_survey/

Schmeidler, K., 2008. Czech Suburbanisation and its Consequences for Mobility and Transport. In International Symposium on Climate Change and Human Settlements : Technology for minimizing CO2 Emissions in the Settlements Areas. National Institute for Land and Infrastructure Management, Ministry of Land, Infrastructure and Transport - Japan, Agency for Research and Development, Ministry of Public Works Indonesia, 18-23 March 2008. Denpasar: Research Center for Human Settlements, 2008, pp. 1-15.

Socialdata, 2006. The New KONTIV® Design [online]. 13 p. [cit. 2009-02-05]. $<$ http://www.socialdata.de/info/KONTIV_engl.pdf $>$

Socialdata, 2009. Mobility Characteristics: Surveys with the KONTIV ® design [online]. 5th February 2009 [cit. 2009-02-05]. <http://www.socialdata.de/daten/mob_e.php>

South African Department of Transport, 2007. National Household Travel Survey [online]. 5th June 2007 [cit. 2009-02-05]. <http://www.transport.gov.za/projects/nts/Default.html>

SWOV, 2009. National Travel Survey (NTS) [online]. 29th January 2009 [cit. 2009-02-05]. $<$ http://www.swov.nl/uk/research/kennisbank/inhoud/90_gegevensbronnen/inhoud/ovg.htm>

Transport for London, 2008. London Travel Demand Survey [online]. 1st April 2008 [cit. 2009-02-05]. $<$ http://www.tfl.gov.uk/corporate/projectsandschemes/communityandeducation/5033.aspx>

\footnotetext{
${ }^{1} \mathrm{http}: / / \operatorname{costc} 27$. altervista.org/
} 